\title{
STRESS-DEFORMED STATE OF A PACKING RING WITH ECCENTRIC HOLES
}

\author{
IIman Hasanov", Ibrahim Abbasov, and Nurlan Gurbanov \\ Azerbaijan State Oil and Industry University, 20 Azadlig Avenue, Baku, Az.1010, AZERBAIJAN \\ \# Corresponding author, ilman.hasanov@mail.ru
}

Communicated by Aleksandrs Šostaks

\begin{abstract}
Currently, various variants of physical and geometrical non-linear calculation of anisotropic bodies have been developed. In spite of the large and increasing number of studies on the theory of shells there are still many unsufficiently developed problems important both in scientific and applied fields, for example, development of practically convenient methods for calculating of anisotropic sealing composite materials weakened by eccentric holes under the influence of local loadings. Stress-deformed state of a packing ring with eccentric holes of sealing materials was studied. In composite materials, the Hookes equation was used for this purpose. Also, using Lurie's symbolic method, the concrete solution of the sealing problem with eccentric holes was obtained.
\end{abstract}

Key words: eccentricity, packing ring, stress, deformation, method of initial function, stress tensor components, Lurie's method, dimensionless geometric parameter.

\section{INTRODUCTION}

Packing rings of composite polymer materials are widely used in the sealing unit on oilfield equipment. Different methods have been used to study such a stress deformation state of the packing: variation of parameters, the calculation of the operation, Muscalevshik's complex variables method and so on. However, mathematical calculation of these methods for such packing either is impossible to be calculated by the methods abovementioned or selected by "constructive selection" approaches of engineering designers. Such approaches have a negative impact on the capacity of packing parts and their efficiency is unproductive. In order to study stress deformation state of the packing, the methods developed according to Hook's law of equations system made for the stresses of elasticity theory are less suitable than the method of startup functions used for the border conditions. The solution of the problem not only meets the terms taking into account the geometric shape and working conditions of the packing, but also it considerably simplifies the number and form of mathematical conversions.

The stress-deformed state of complex geometric forms of packer with eccentric holes from composite polymer materials was determined by the method of initial functions in the elasticity theory for complex packers.
Derivative constants entering unit general were determined from boundary conditions at the edges of limned sealing in the direction $\rho_{1}$. Various methods satisfying boundary conditions on the basis of variation equations of the mixed principle of Reisner stationary can be used for this. Point satisfaction of boundary conditions is orthogonalisation of the row related to any complete system of functions. Thus, solution of initial functions by the obtained method is precise. The aim of the paper was to provide a complete solution of the system of equations obtained by the method of initial functions and the boundary conditions at the edge.

\section{METHODS}

For the considered packer, differential equilibrium equations and the equation of Hook's law were written. Sizeless parameters of geometric and statistic values were accepted and symbols of differentiation on variables $(r$ and $\varphi)$ were introduced.

The symbolic operating method of system integrating at initial conditions on the plane was applied and operation of the initial values was determined. Composite polymer materials are widely used in the packing unit of the packing rings of oil-field equipment. Their application efficiency 
largely depends on the stress state of the seal (Avrushenko, 1978; Naushirovanov, 1991; Razina et al., 1991). Influence of excentricity of stress deformation on the condition of the packing has not been studied sufficiently. Study of the deformation processes on structurally homogeneous composite packing is the subject of the formation of a new model of real composite packing, where parameters determining properties of elasticity are the method of initial coordinates. All these make possible to carry out all round analyses of this method:

1. Considering components of the stress tensor and transmission vector, corresponding to coordinate directions the model based on differential equations of equilibrium was developed built and the Hook's law was written for the coefficients of elasticity for the plane strained condition and in the case of plane deformation;

Using the method of initial functions for solving the problem:

2. A method was proposed for calculating the boundary value problem of a static, geometric or mixed type of homogeneous and nonnhomogeneous boundary conditions.

Thus, the solution of a boundary problem with nonhomogeneous conditions (static, geometric or mixed type) at the edges $\varphi=0$ and $\varphi=\varphi_{a}$ can be obtained by imposing a particular solution satisfying all the boundary conditions set at these edges and a general solution of the corresponding homogeneous boundary problem where, according to the method of initial functions, solutions of some nonhomogeneous boundary-value problems for anisotropic bodies of sealing composite materials are constructed (Vlasov, 1960; Kutz, 2011; Babanli et al., 2016; Mammadov, 2016).

Let us consider a packing O-ring having cylindrical coordinates $(r, \varphi, z)$ with eccentric holes (Fig. 1).

Let us write differential (Grin et al., 1965; Hasanov, 2016; Aslanov et al., 2017) equations of equilibrium (in the absence of mass forces) and the Hooke's equation for the plane problem of the theory of elasticity in the form:

$\frac{\partial\left(r \sigma_{r}\right)}{\partial r}-\sigma_{\varphi}+\frac{\partial \tau_{r \varphi}}{\partial \varphi}=0 ; \frac{\partial\left(r \tau_{r \varphi}\right)}{\partial r}+\tau_{r \varphi}+\frac{\partial \sigma_{\varphi}}{\partial \varphi}=0 ;$

$\frac{\partial u}{\partial r}=b_{11} \sigma_{r}+b_{12} \sigma_{\varphi} ; \frac{1}{r} \cdot \frac{\partial u}{\partial \varphi}+\frac{u}{r}=b_{21} \sigma_{r}+b_{22} \sigma_{\varphi} ;$

$\frac{1}{r} \cdot \frac{\partial u}{\partial \varphi}+\frac{\partial \vartheta}{\partial r}-\frac{\vartheta}{r}=\frac{1}{G_{12}} \cdot \tau_{r \varphi}$

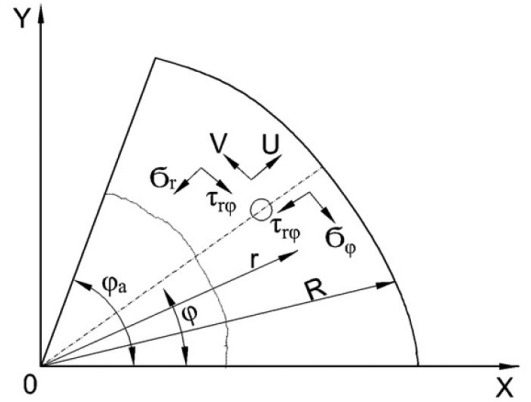

Fig. 1. The design scheme of the stress-deformed state of an eccentric composite packing ring. where $\sigma_{r}(r, \phi) ; \sigma_{\varphi}(r, \varphi)$ and $\tau_{r \phi}(r, \phi)$ are the stress tensor components; and are the displacement vector components corresponding to the coordinate directions $r$ and $\varphi$. For the coefficients of elasticity $b_{i j}(i, j=1,2)$ we have:

$b_{11}=\frac{1}{E_{1}} ; b_{22}=\frac{1}{E_{2}} ; b_{12}=b_{21}=\frac{v_{21}}{E_{2}}=\frac{v_{12}}{E_{1}}$.

In the case of plane deformation

$b_{11}=\frac{\left(1-v_{13} v_{31}\right)}{E_{1}} ; b_{22}=\frac{\left(1-v_{23} v_{32}\right)}{E_{2}} ; b_{12}=b_{32}=\frac{v_{12}+v_{13} v_{32}}{E_{1}}$.

Here through $E_{i}(i=1,2), G_{12}$ and $v_{i j}(i, j=1,2,3 ; i \neq j)$ we donote the tensile and compression modulus, shear modulus and Poisson's ratio; indices 1,2,3 at technical elastic constants correspond to main elastic directions $r, \varphi, z$ (Kupradze et al., 1976; Natroshvili et al., 1978).

Let us write a new variable $\tau$ connected with variable $r$ by formula:

$\tau=\ln \rho ; \rho=\frac{r}{R} e^{\tau}$

where $\rho$ is a dimensionless radius (current radius related to the external radius).

For simplification let us write

$\xi=\frac{1}{\sqrt{b_{11} b_{22}}} ; \theta=\sqrt{b_{22} / b_{11}} ; \delta=1 / \theta ; v=\xi \sqrt{b_{12} b_{21}} ;$

$\chi=\left(\xi / G_{12}-2 v\right) / 2$.

and instead of $u, \sigma_{r}, \sigma_{\varphi}, \tau_{r \varphi}$ we will further consider dimensionless geometric and statistic parameters

$\phi_{1}=u / R ; \phi_{2}=\vartheta / R ; \phi_{3}=b_{11} \rho \sigma_{\varphi} ; \phi_{4}=b_{11} \rho \tau_{r \varphi} ;$

$\phi_{5}=b_{11} \rho \sigma_{r}$

Moreover, let us write symbols of differentiation on variables $\tau$ and $\varphi$ :

$\alpha^{n}=\partial^{n} / \partial \tau^{n} ; \beta^{n}=\partial^{m} / \partial \varphi^{m}$.

Considering relations (2), (5) we will rewrite system of equations (1) in the form:

$\alpha \phi_{5}-\phi_{3}+\beta \phi_{4}=0 ;(\alpha+1) \phi_{4}+\beta \phi_{3}=0 ;$

$\alpha \phi_{1}=\phi_{5}-v \theta \phi_{3}=0$;

$\beta \phi_{2}+\phi_{1}=\theta\left(\theta \phi_{3}-v \phi_{5}\right)$;

$\beta \phi_{1}+(\alpha-1) \phi_{2}=2 \theta(\chi+v) \phi_{4}$.

\section{FINDINGS}

General solution of the boundary task of inhomogeneous conditions (statistic, geometric or mixed type) on the edges of packer $\varphi=0$ and $\varphi=\varphi_{a}$ can be obtained by finding the solution satisfying all set up boundary conditions at the edges and the general solution corresponding to initial boundary task. The solution can be determined by the method shown in the system of equations (1) where solu- 
tions of some nonhomogeneous boundary tasks for an isotopic object (packer) have been set up due to the method of initial functions.

\section{TASK SOLUTION}

Applying the symbolic (operational) Lurie's method (Lurye, 1970; Golubev et al., 1986; Gurbanov, 1991) by integrating the system (6) under the initial conditions on the plane $\varphi=0$

$\phi_{j}(\tau, 0)=\phi_{j}^{0},(j=1,2,3,4)$

we will get basic dependences of the method of initial functions in the form of the following transformation of the initial functions $\phi_{j}^{0}$ into the required ones:

$\phi_{i}(\tau, \varphi)=\sum_{j=1}^{4} L_{i j}(\alpha, \varphi) \phi_{j}^{0}(i=1,2,3,4)$

We determine the operators $L_{i j}(\alpha, \varphi)$ by formulae:

$L_{11}=\frac{C_{1} P_{1}-C_{2} P_{2}}{K} ; L_{12}=\frac{(\alpha-1)\left(S_{2} P_{2} / K_{2}-S_{1} P_{1} / K_{1}\right)}{K} ;$

$L_{13}=\frac{P_{1} P_{2} \cdot\left(C_{1}-C_{2}\right)}{\left[K \alpha^{2}(\alpha+1)\right]} ; L_{14}=\frac{\left(S_{1} P_{1} Q_{1} / K_{1}-S_{2} P_{2} Q_{2} / K_{2}\right.}{\left(K \alpha^{2}\right)} ;$

$L_{21}=\frac{\left(S_{2} Q_{1} K_{2}-S_{1} Q_{2} K_{1}\right)}{K} ; L_{22}=\frac{\left(C_{2} Q_{1}-C_{1} Q_{2}\right)}{K} ;$

$L_{23}=\frac{\left(S_{2} P_{1} Q_{1} K_{2}-S_{1} P_{2} Q_{2} K_{1}\right)}{K} ; L_{24}=\frac{Q_{1} Q_{2}\left(C_{1}-C_{2}\right)}{\left[K \alpha^{2}(\alpha-1)\right]} ;$

$L_{32}=\frac{\alpha^{2}\left(\alpha^{2}-1\right)\left(S_{1} / K_{1}-S_{2} / K_{2}\right)}{K} ; L_{33}=\frac{\left(C_{2} P_{1}-C_{1} P_{2}\right)}{K} ;$

$L_{34}=\frac{(\alpha+1)\left(S_{2} Q_{2} / K_{2}-S_{1} Q_{1} / K_{1}\right)}{K} ;$

$L_{41}=\alpha^{2}\left(S_{2} K_{2}-S_{1} K_{1}\right) K ; L_{42}=\frac{\alpha^{2}(\alpha-1)\left(C_{2}-C_{1}\right)}{K} ;$

$L_{51}=\frac{\alpha\left(C_{2} T_{1}-C_{2} T_{2}\right.}{K} ; L_{52}=\frac{\alpha(\alpha-1)\left(S_{2} T_{2} K_{2}-S_{1} T_{1} K_{1}\right)}{K} ;$

$L_{53}=\frac{\left(C_{1} P_{2} T_{1}-C_{2} P_{1} T_{2}\right)}{[K \alpha(\alpha+1)]} ;$

$L_{54}=\frac{\left(S_{1} Q_{1} T_{1} / K_{1}-S_{2} Q_{2} T_{2} / K_{2}\right)}{K \alpha}$.

where it is indicated

$K_{i}=\left[1+\chi\left(\alpha^{2}+(-1)^{i} \alpha\right) \sqrt{1+2 \chi \theta+\theta^{2}+\left(\chi^{2}-1\right) \theta^{2} \alpha^{2}}\right]^{\frac{1}{2}} ;$

$Q_{i}=K_{i}^{2}+(\alpha-1)(1+v \theta \alpha) ; P_{i}=K_{i}^{2}-(\alpha-1)(1-v \theta \alpha) ;$

$T_{i}=K_{i}^{2}-(\alpha-1) ; S_{i}=\operatorname{Sin}_{i} \cdot \varphi ;(i=1,2) ; K=K_{1}^{2}-K_{2}^{2}$.

\section{ANALYSIS OF RESULTS}

Introducing the conditions of correspondence between the operators $\alpha-1$ and $\alpha+1, P_{i}$, and $Q_{i}$, it can be noted that the formulas for the operators $L_{i j}$ located symmetrically with respect to the secondary diagonal of the transformation matrix (8), go one into the other:

$L_{31} \leftrightarrow L_{42} ; L_{21} \leftrightarrow L_{43} ; L_{11} \leftrightarrow L_{44} ; L_{221} \leftrightarrow L_{33} ; L_{12} \leftrightarrow L_{34} ;$

$L_{13} \leftrightarrow L_{24}$

This property of operators $S_{1}$ and $C$ can be presented into series of:

$$
\begin{aligned}
& S_{i}=\sum_{n=0}^{\infty}(-1)^{n} \frac{\left(K_{i} \varphi\right)^{2 n+1}}{(2 n+1) !} \cdot \beta^{n+1} ; \\
& C_{i}=1+\sum_{n=1}^{\infty}(-1)^{n} \frac{\left(K_{i} \varphi\right)^{2 n}}{(2 n) !} \cdot \beta^{2 n}
\end{aligned}
$$

Using dependencies (8) and (10) for the desired functions, we can obtain expressions in the form of power series in the angular coordinate $\varphi$, the coefficients of which are the values of various combinations of operators $\alpha, \alpha \pm 1, K, K_{i}, P_{i}$, $Q_{i}$ and $T_{i}$ over the initial functions. In turn, the operators $K, K_{i}, P_{i}, Q_{i}$ and $T_{i}$ can be formally decomposed into rows as ordinary irrational functions from $\alpha$.

\section{SOLUTION FOR ANOTHER CONDITION}

Let us suppose that on $\varphi=0$ and $\varphi=\varphi_{a}$ a set of homogeneous boundary conditions (geometric, static or mixed) is given as

$\phi_{\partial}=\phi_{n}=0$ in $\varphi=0$;

$\phi_{p}(r, \varphi)=\phi_{q}\left(\tau, \varphi_{a}\right)=0$ in $\varphi=\varphi_{a}$.

Let us indicate two unknown initial function $\phi_{s}^{0}$ and $\phi_{i}^{0}$ without concretising values of the indices $g, h, p$ and $q$.

Considering condition (11) instead of dependence (8) we have

$\phi_{i}=L_{i s}(\alpha, \varphi) \phi_{s}+L_{i t}(\alpha, \varphi) \phi_{t}^{0}(i=1,2,3,4,5)$.

From the dependence (13) considering condition (12) we get the system of two ordinary differentials transcendent equations relatively to $\phi_{s}^{0}$ and $\phi_{i}^{0}$.

$L_{p s}\left(\alpha, \varphi_{a}\right) \phi_{s}^{0}+L_{p t}\left(\alpha, \varphi_{a}\right) \phi_{t}^{0}=0 ;$

$L_{q s}\left(\alpha, \varphi_{a}\right) \phi_{s}^{0}+L_{q t}\left(\alpha, \varphi_{a}\right) \phi_{t}^{0}=0$.

Putting the decision function $F(\tau)$ by the formulas

$\phi_{s}^{0}=L_{p t}\left(\alpha, \varphi_{a}\right) F ; \phi_{t}^{0}=-L_{p s}\left(\alpha, \varphi_{a}\right) F$

we will bring the system (14) to a resolving equation

$L_{q s}\left(\alpha, \varphi_{a}\right) L_{p t}\left(\alpha, \varphi_{a}\right)-L_{q t}\left(\alpha, \varphi_{a}\right) \cdot L_{p s}\left(\alpha, \varphi_{a}\right) F=0$.

Considering formula (15) instead of the dependence (13), we get

$\phi_{i}=\left\lfloor L_{i s}(\alpha, \varphi) L_{p t}\left(\alpha, \varphi_{a}\right)-L_{i t}(\alpha, \varphi) L_{p s}(\alpha, \varphi)\right\rfloor F$. 
The solution of equation (16) we find in the form $F=e^{\lambda \tau}$. To determine $\lambda$ we have the characteristic transcendental equation

$L_{q s}\left(\lambda, \varphi_{a}\right) L_{p t}\left(\alpha, \varphi_{a}\right)-L_{q t}\left(\lambda, \varphi_{a}\right)=0$.

We will obtain the equation of specific boundary value problems solutions (18) by assigning the corresponding values to the indices $\mathrm{g}, \mathrm{h}, \mathrm{p}, \mathrm{q}, \mathrm{s}, \mathrm{t}$. These equations are given in Table 1, where

$K_{1,2}=\left[1+\chi \theta \lambda^{2}=\lambda \sqrt{\left(1+2 \chi\left(\theta+\theta^{2}\right)+\left(\chi^{2}-1\right) \theta^{2} \lambda^{2}\right)^{1 / 2}}\right]$
$\omega_{1,2}=k_{1} \pm k_{2} ; \varepsilon_{1,2}=2 k_{1} k_{2}(\chi+v) \pm \theta\left(\lambda^{2}-1\right)\left(1-v^{2}\right)$.

Applying in expression (17) the general integrals for $F$ corresponding to the characteristic numbers of a particular boundary value problem, it is not difficult to obtain the corresponding general integrals for $\phi_{i}(i=1,2,3,4,5)$.

However, in the case of a boundary value problem with homogeneous static conditions at the edges $\varphi=0$ and $\varphi=\varphi_{a}$, the characteristic equation (18) has four multiple zero roots $\lambda(1,2,3,4)$ and two roots $\lambda= \pm 1$, which, unlike other roots, do not depend on the angle $\varphi_{a}$. The general integral for $F$, determined by these roots is:
$F=A_{1}+A_{2} \tau+A_{3} \tau^{2}+A_{4} \tau^{3}+A_{2} \tau^{4}+A_{6} \tau^{5}$

When substituting integral (19) into expression (17), the part of the solution corresponding to arbitrary constants $A_{1}$ and $A_{2}$ is lost as a result of differentiation.

Therefore, in determining common integrals $\phi_{i}$ corresponding to multiple zero characteristic numbers, we should proceed directly from dependence (13) and equation (14). Representing in system (14) transcendental operators in the form of series, restricted in these series only the first members, we obtain two independent differential equations for the unknown initial functions $\phi_{1}^{0}$ and $\phi_{2}^{0}$ :

$\alpha^{r} \phi_{1}^{0}=0 ; \alpha^{r} \phi_{2}^{0}=0$.

From these equations we find

$\phi_{1}^{0}=A_{1}+A_{2} \tau ; \phi_{2}^{0}=A_{3}+A_{4} \tau$,

where $A_{i}(i=1,2, \ldots)$ are arbitrary constants. Substituting the expression (20) into the dependence (13) we get the integrals for $\phi_{i}$, corresponding to the four multiple zero roots of equation (18). We find integrals for $\phi_{i}$ determined by the roots $\lambda_{5,6}= \pm 1$. As a result from the equation (17) for $\phi_{i}$, meeting elementary typical numbers $\lambda_{1,2, \ldots 6}$, we write

Table 1

\begin{tabular}{|c|c|c|c|}
\hline $\begin{array}{l}\text { Boundary } \\
\text { condition }\end{array}$ & $\varphi=0$ & $\varphi=\varphi_{a}$ & $\begin{array}{l}L_{q s}\left(\lambda, \varphi_{a}\right) L_{p i}\left(\lambda, \varphi_{a}\right)- \\
-\operatorname{L\varphi t}\left(\lambda, \varphi_{a}\right) L_{p s}\left(\lambda, \varphi_{a}\right)=0\end{array}$ \\
\hline 1 & $\vartheta=\tau_{r p}=0$ & $\vartheta=\tau_{r \varphi}=0$ & $\theta^{2} \lambda^{2}-1 / k_{1} k_{2} \cdot \sin k_{1} \varphi_{0} \sin k_{2} \varphi_{a}=0$ \\
\hline 2 & $u=\sigma_{\varphi}=0$ & $u=\sigma_{\varphi}=0$ & $\frac{\lambda^{2}-1}{k_{1} k_{2}} \sin k_{1} \varphi_{a} \sin k_{2} \varphi_{a}=0$ \\
\hline 3 & $u=\sigma_{\varphi}=0$ & $\vartheta=\tau_{r \varphi}=0$ & $\cos k_{1} \varphi_{a} \cos k_{2} \varphi_{a}=0$ \\
\hline 4 & $\vartheta=\tau_{r \varphi}=0$ & $u=\sigma_{\varphi}=0$ & $\cos k_{1} \varphi_{a} \cos k_{2} \varphi_{a}=0$ \\
\hline 5 & $\sigma_{\varphi}=\tau_{r \varphi}=0$ & $\tau_{r \varphi}=\sigma_{\varphi}=0$ & $\frac{\lambda^{4}\left(\lambda^{2}-1\right)}{k_{1} k_{2}} \cdot \sum_{i=1}^{2}(-1)^{i}\left(\frac{1}{\omega_{i}} \sin \frac{\omega_{2} \varphi_{a}}{2}\right)^{2}=0$ \\
\hline 6 & $\vartheta=\tau_{r \varphi}=0$ & $\sigma_{\varphi}=\tau_{r \varphi}=0$ & $\lambda^{2} \sum_{i=1}^{2} \frac{1}{\omega_{i}} \sin \omega_{i} \varphi_{a}=0$ \\
\hline 7 & $\sigma_{\varphi}=\tau_{r \varphi}=0$ & $\vartheta=\tau_{r \varphi}=0$ & $\lambda^{2} \sum_{i=1}^{2} \frac{1}{\omega_{i}} \sin \omega_{i} \varphi_{a}=0$ \\
\hline 8 & $u=\sigma_{\varphi}=0$ & $\sigma_{\varphi}=\tau_{r \varphi}=0$ & $\lambda^{2}\left(\lambda^{2}-1\right) \sum^{2}(-1)^{i} \frac{1}{\sin \omega \phi}$ \\
\hline 9 & $\sigma_{p}=\tau_{r p}=0$ & $u=\sigma_{p}=0$ & $k_{1} k_{2} \sum_{i=1}(-1) \overline{\omega_{i}} \sin \omega_{i} \varphi_{a}$ \\
\hline 10 & $u=\vartheta=0$ & $u=\sigma_{\varphi}=0$ & $1 \sum^{2} \frac{\varepsilon_{i}}{i} \sin \omega \varphi=0$ \\
\hline 11 & $u=\sigma_{\varphi}=0$ & $u=\vartheta=0$ & $k_{1} k_{2} \sum_{i=1} \omega_{i}$ \\
\hline 12 & $u=\vartheta=0$ & $\vartheta=\tau_{r \varphi}=0$ & $1 \sum^{2}(-1)^{i} \frac{\varepsilon_{i}}{-} \sin \omega . \varphi=0$ \\
\hline 13 & $\vartheta=\tau_{r \varphi}=0$ & $u=\vartheta=0$ & $\lambda^{2}-1 \sum_{i=1} \quad \omega_{i}$ \\
\hline 14 & $u=\vartheta=0$ & $u=\vartheta=0$ & $\frac{1}{k_{1} k_{2}\left(\lambda^{2}-1\right)} \sum_{i=1}^{2}(-1)^{i}\left(\frac{\varepsilon_{i}}{\omega_{i}} \sin \frac{\omega \varphi_{a}}{2}\right)^{2}=0$ \\
\hline 15 & $u=\vartheta=0$ & $\sigma_{\varphi}=\tau_{r \varphi}=0$ & $\lambda^{2} \sum^{2} \varepsilon_{\cdot}\left(\frac{1}{\sin } \frac{\omega_{i} \varphi_{a}}{{ }^{2}-1=0}\right.$ \\
\hline 16 & $\sigma_{\varphi}=\tau_{r \varphi}=0$ & $u=\vartheta=0$ & $\overline{k_{1} k_{2}} \sum_{i=1}^{\tilde{\sigma}_{i}\left(\bar{\omega}_{i}\right.} \mathrm{Dul} \quad 2$ \\
\hline
\end{tabular}




$$
\begin{aligned}
& \phi_{1}=\frac{A_{1} \cos \varphi+\mathrm{A}_{2}\left(\theta_{1} \varphi \sin \varphi+\ln \rho \cos \varphi\right)+A_{3} \sin \varphi-}{\rho} \\
& \frac{-\mathrm{A}_{4}\left[\left(\theta_{2}-\ln \rho\right) \sin \varphi+\theta_{1} \varphi \cos \varphi\right]+A_{6} \theta_{3}\left[\cos \theta_{3} \varphi-\right.}{\rho} \\
& \frac{\left.-\cos \theta_{3}\left(\varphi-\varphi_{\alpha}\right)\right]}{\rho}, \\
& \phi_{2}=\frac{-A_{1} \sin \varphi+\mathrm{A}_{2}\left[\theta_{1} \varphi \cos \varphi-\left(\theta_{2}+\ln \rho\right) \sin \varphi\right]+}{\rho} \\
& \frac{+A_{3} \cos \varphi+\mathrm{A}_{2}\left[\left(\theta_{1} \varphi \cos \varphi-\left(\theta_{2}+\ln \rho\right) \sin \varphi\right]+A_{3} \cos \varphi+\right.}{\rho} \\
& \frac{+A_{4}\left(\theta_{1} \sin \varphi+\ln \rho \cos \varphi+A_{5} \rho+2 A_{6}\left\{\theta _ { 1 } \left[\sin \theta_{3}\left(\varphi-\varphi_{a}\right)-\right.\right.\right.}{\rho} \\
& \frac{\left.\left.-\sin \theta_{3} \varphi\right]+\left(\theta_{1}-\theta_{3}^{2} / 4\right) \sin \theta_{3} \varphi_{a}\right\}}{\rho}, \\
& \phi_{3}=0 ; \phi_{4}=\frac{A_{6}\left[\sin \theta_{3}\left(\varphi-\varphi_{a}\right)-\sin \theta_{3} \varphi+\sin \theta_{3} \varphi_{a}\right]}{\rho}, \\
& \phi_{5}=\frac{A_{2} \cos \varphi+A_{4} \sin \varphi+\mathrm{A}_{6} \theta_{3} \cdot\left[\cos \theta_{2}\left(\varphi-\varphi_{a}\right)-\right.}{\rho} \\
& \frac{\left.-\cos \theta_{3} \varphi\right]}{\rho},
\end{aligned}
$$

where

$$
\theta_{1}=(1-v \theta) / 2 ; \theta_{2}=(1+v \theta) / 2 ; \theta_{3}=\sqrt{2(1+\chi \theta)} \text {. }
$$

For the remaining homogeneous boundary value problems whose characteristic equations have real roots independent of $\varphi_{a}$, the corresponding elementary solutions are given in Table 2.

These solutions, including those determined by multiple zero characteristic numbers, are in a common way. In the case of boundary conditions 7 or 9 (see Table 1) in the corresponding formulas of Table $2, \varphi$ should be replaced by $\varphi-\varphi_{a}$. It is not difficult to find out the mechanical meaning of separate parts of the obtained elementary solutions. For example, in the general solution (21), the part of this solution defined by the constants $A_{1}, A_{3}$ and $A_{5}$ corresponds to rigid displacements and rotations in the plane $(\rho, \varphi)$, the other part of the solution with constants $A_{2}$ and $A_{4}$ corresponds to the solution for the sealing ring with an eccentric hole, loaded by a lateral concentrated force, and finally, part of the solution with constant $A_{6}$ corresponds to the solution for a packing ring with an excentric hole loaded by a concentrated bending moment. The angle-dependent characteristic numbers $\varphi_{a}$ of boundary problems with homogeneous mixed conditions at the edges $\varphi=0$ and $\varphi-\varphi_{a}$ are determined from ratios

$k_{1,2}=d_{n}(n=1,2, \ldots, \infty)$,

\begin{tabular}{|c|c|c|}
\hline$\varphi=0$ & $\varphi=\varphi_{a}$ & $\lambda_{1} \phi_{i}(i=1,2,3,4,5)$ \\
\hline $\begin{array}{l}\vartheta=0 \\
\tau_{r \varphi}=0\end{array}$ & $\begin{array}{l}\vartheta=0 \\
\tau_{r \varphi}=0\end{array}$ & $\begin{array}{l}\lambda_{1,2}= \pm \delta ; \phi_{1}=A_{1}(1-v) \rho^{\delta}+A_{2}(1+v) / \rho^{\delta} \\
\phi_{2}=\phi_{4}=0 ; \phi_{3}=\delta^{2}\left(A_{1} \rho^{\delta}+A_{2} / \rho^{\delta}\right) \\
\phi=\delta\left(A_{1} \rho^{\delta}-A_{2} / \rho^{\delta}\right)\end{array}$ \\
\hline $\begin{array}{l}u=0 \\
\sigma_{\varphi}=0\end{array}$ & $\begin{array}{l}u=0 \\
\tau_{r \varphi}=0\end{array}$ & $\begin{array}{l}\lambda_{1,2}= \pm 1 ; \phi_{1}=\phi_{3}=\phi_{5}=0 \\
\phi_{2}=A_{1 p}+\theta(\chi+v) A_{2} / \rho ; \phi_{4}=-A_{2} / \rho\end{array}$ \\
\hline $\begin{array}{l}\vartheta=0 \\
\tau_{r \varphi}=0\end{array}$ & $\begin{array}{l}\sigma_{\varphi}=0 \\
\tau_{r \varphi}=0\end{array}$ & $\begin{array}{l}\lambda_{1,2}=0 ; \phi_{1}=\left(A_{1}+A_{2} \ln \rho\right) \cos \varphi+\theta_{1} A_{2} \varphi \sin \varphi \\
\phi_{2}=-\left(A_{1}+A_{2} \ln \rho\right) \sin \varphi-\left(\theta_{2} \sin \varphi-\theta_{1} \varphi \cos \varphi\right) A_{2}\end{array}$ \\
\hline $\begin{array}{l}\sigma_{\varphi}=0 \\
\tau_{r \varphi}=0\end{array}$ & $\begin{array}{l}\vartheta=0 \\
\tau_{r \varphi}=0\end{array}$ & $\phi_{3}=\phi_{4}=0 ; \phi_{5}=A_{2} \cos \varphi$ \\
\hline $\begin{array}{l}u=0 \\
\sigma_{\varphi}=0\end{array}$ & $\begin{array}{l}\sigma_{\varphi}=0 \\
\tau_{r \varphi}=0\end{array}$ & $\begin{array}{l}\lambda_{1,2}=0 ; \lambda_{3,4}= \pm 1 \\
\phi_{1}=\left(A_{1}+A_{2} \ln \rho\right) \sin \varphi-\left(\theta_{2} \sin \varphi+\theta_{1} \varphi \cos \varphi\right) A_{2}+\left(2 A_{4} \theta_{3} \sin \theta_{3} \varphi / \rho\right)\end{array}$ \\
\hline $\begin{array}{l}\sigma_{\varphi}=0 \\
\tau_{r \varphi}=0\end{array}$ & & $\begin{array}{l}\phi_{2}=\left(A_{1}+A_{2} \ln \rho\right) \cos \varphi+\theta_{1} A_{2} \varphi \sin \varphi+A_{3} p+A_{4}\left[4 \theta_{1} \cos \theta_{3} \varphi+\left(\theta_{3}^{2}-4 \theta_{1}\right) \cos \theta_{3} \varphi_{a}\right] \rho \\
\phi_{3}=0 ; \phi_{4}=2 A_{4}\left(\cos \theta_{3} \varphi-\cos \theta_{3} \varphi_{a}\right) / \rho ; \\
\phi_{3}=A_{2} \sin \varphi-\left(2 A_{4} \theta_{3} \sin \theta_{3} \varphi\right) / \rho\end{array}$ \\
\hline
\end{tabular}

where in the case of boundary conditions 1 or 2 (see Table 1) $d_{n}=\pi n / \varphi_{a}$; in the case of boundary conditions 3 and 4 (see Table 1) $d_{n}=\pi\left(n-\frac{1}{2}\right) / \varphi_{a}$. Hence, we find the following values of characteristic numbers:

$\lambda_{1,2,3,4}= \pm\left(\delta_{n} \pm \sqrt{\delta_{1 n} \delta_{2 n}}\right)^{\frac{1}{2}} / \sqrt{2 \theta}$

where it is indicated

$\delta_{n}=2 \chi d_{n}^{2}+\theta+\delta$

$\delta_{1 n}=\delta_{n}-2\left(d_{n}^{2}-1\right)=(\sqrt{\theta}-\sqrt{\delta})^{2}+2 d_{n}^{2}(1+\chi) ;$

Table 2 
$\delta_{2 n}=\delta_{n}-2(\sqrt{\theta}+\sqrt{\delta}) / \sqrt{2(1-\chi)}$, we have complex characteristic numbers $\lambda_{n 1,2,3,4}= \pm\left(b_{n} \pm i c_{n}\right)$,

where

$n_{n}=\frac{1}{2} \sqrt{\delta_{1 n} / \theta} ; c_{n}=\frac{1}{2} \sqrt{-\delta_{2 n} / \theta} ; i=\sqrt{-1}$.

General integrals for $\phi_{i}(i=1,2,3,4,5)$ corresponding to these characteristic numbers are represented according to dependence (17) in the form

$$
\begin{aligned}
\phi_{i} & =\sum_{n=1}^{\infty} \sum_{j=1}^{4} A_{i j}\left[L_{i s}\left(\lambda_{n j}, \varphi\right) L_{p t}\left(\lambda_{n j}, \varphi_{a}\right)-\right. \\
& \left.-L_{i t}\left(\lambda_{n j}, \varphi\right) L_{p s}\left(\lambda_{n j}, \varphi_{a}\right)\right] \cdot \rho^{\lambda_{n j}}+ \\
& +\sum_{m} \sum_{k=1}^{2} A_{m k}\left[L_{i s}\left(\lambda_{m k}, \varphi\right) L_{p t}\left(\lambda_{m k}, \varphi_{a}\right)-\right. \\
& \left.-L_{i t}\left(\lambda_{m k}, \varphi\right) L_{p s}\left(\lambda_{m k}, \varphi_{a}\right)\right] \cdot \rho^{\lambda_{m k}}
\end{aligned}
$$

where $A_{n j}, A_{m k}$ are arbitrary constants.

\section{CONCLUSIONS}

1. The conclusion obtained by the method of initial functions solution satisfies exactly the system of equations (1) and boundary conditions at the edges $\varphi=0$ and $\varphi=\varphi_{a}$.

2. If in the solution obtained, the functions from $\varphi$ are orthogonal, then the boundary conditions at the edges $\rho_{1}=a$ and $\rho_{2}=b$ can be satisfied exactly, otherwise the boundary conditions at the edges bounding the body in the direction $\rho$ are approximately satisfied.

\section{REFERENCES}

Aslanov, J. N., Mammadov, Kh. S. (2017). Increasing reliabilty of the improved machines and equipment determination of productivity criteria. Bull. Environ. Pharm. Life Sci., 7 (1), 53-58.

Avrushenko, В. Kh. (1978). Rubber Seals [Аврушенко, Б. Х. Резиновые уплотнители]. Khimiya, Leningrad. 136 pp. (in Russian).

Babanli, M. (2016). Impact of thermoelastic deformation on work of rotating preventers sealing / and others. In: Science and Education: Materżals of the XII International Research and Practice Conference. Munich, pp. 42-54.

Golubev, A. I., Kondakova, L.A. (1986). Seals and Sealing Technology [Голубев, А. И. Уплотнения и уплотнительная техника]. Mashinostroenie, Moscow, 236 pp. (in Russian).
Grin, A., Adkins, D. (1965). Large Elastic Deformations and Nonlinear Mechanics of the Continuous Medium [Грин, А., Адкинс, Дж. Большие упругие деформации и нелинейная механика сплошной среды]. Mir, Moskva, pp. 55-60 (in Russian).

Gurbanov, R. S. (1991). Investigation of the self-sealing effect in packers with saxial holes [Гурбанов, Р. С. Исследование эффекты самоуплотнения в пакерах с упругим элементом с аксиальными отверстиями]. Proceedings of the Higher Educational Institutions "Oil and Gas" [Известия высших учебных заведений “Нефть и газ”] (Baku), 5, 86-89 (in Russian).

Hasanov, I. I. (2016). Assessment of vibration influence on packing system of Christmas tree. Modern Sci. J., 7, 18-22.

Kupradze, V. D., Hegelia, T. G., Basheeleyshvili, M. O., Burchuladze, T. V. (1976). Three-Dimensional Problems of the Mathematical Theory of Elasticity and Thermoelasticity. Classical and Micropolar Theory. Statics, Harmonic Oscillations, and Dynamics. Foundations and Methods of Solution [Купрадзе, В. Д., Гегелия, Т. Г., Башхелейшвили, М. О., Бурчуладзе, Т. В. (1976). Трехмерные задачи математической теории упругости и термоупругости. Классическая и микрополярная теория. Статика, гармонические колебания и динамика. Основы и методы решения]. Nauka, Moskva, 663 pp. (in Russian)

Kutz, M. (2011). Applied Plastics Engineering Handbook. Processing and Materials. Elsevier. 661 pp.

Lurye A. I. (1970). The Theory of Elasticity [Лурье, А. И.Теория упругости]. Nauka, Moskva. 939 pp. (in Russian).

Mammadov, V. T. (2016). Investigation of stress-deformed state of coated hydrocylinders, exposed to pressure and temperature changes. Int. J. Curr. Res., 8 (12), 44212-44216.

Natroshvili, D. G., Jagmaidze, A. Ya. (1978). Dynamic Problems of the Theory of Elasticity for Piecewise Homogeneous Bodies. Tbilisi University Press, Tbilisi. 64 pp.

Naushirovanov, R. G. (1961). Sealing Equipment Used in Oil Refining and Petrochemical Industries in the USSR and Abroad. Pump Building. XM-4: Review Information [Наушированов, Р. Г. Уплотнительная техника, применяемая на нефтеперерабатьвающих и нефтехимических производствах в СССР и за рубежом. Насосостроение. ХМ-4: Обзорниная информация]. Central Institute of Scientific Technical Information Khimneftemash, Moscow. 61 pp. (in Russian).

Razina, V. V., Gurov, A. A., Smirnov, A. N., Viviurskii, A. V. (1991). Sealing Compositions Based on Chemically Modified PTFE. Plastics, No. 10 [Разина, В. В., Гуров, А. А., Смирнов, А. Н., Вивюрский, А. В. Уплотнительные композииии на основе химически модифииированного ПТФЭ. Пластические массы, 10]. Khimiya, Moscow. 29 pp. (in Russian).

Vlasov, V. V. (1975). Method of Initial Functions in Problems of the Theory of Elasticity and Structural Mechanics [Власов, В. В. Метод начальных функций в плоской задаче теории управления]. Stroyizdat, Moscow. 223 pp. (in Russian).

\section{BLĪVĒJUMA GREDZENA SPRAIGI DEFORMĒTAIS STĀVOKLIS AR EKSCENTRISKAJIEM CAURUMIEM}

Rakstā pētīti blīvējuma gredzena spraigi deformētie stāvokḷi ar blīvējuma materiālu ekscentriskajiem caurumiem. Kompozītmateriālos šim nolūkam izmanto Guka vienādojumu. Izmantojot Lurijas simbolisko metodi, ir iegūts konkrēts risinājums blīvējuma problēmai ar ekscentriskiem caurumiem. 